attractive waterbird, better known to the British as the great northern diver (and hero of Arthur Ransome's children's book Great Northern). Thomson discusses the role of the loon, his backyard equivalent of the giant panda or tiger, as a flagship species, a marker for environmental disturbance (which is why this once Common species is Less Frequent).

Indeed, are we doing enough to fulfil our nineteenth-century predecessors' perception of the need to collect, record and then understand the diversity of nature, especially now that the rate of anthropogenic extinction is so much higher? It will do the average physicist good to see how biological and palaeontological research, too often condemned as 'stamp collecting' (itself, as Thomson notes, only too common in the physical sciences), answers and raises further profound and difficult questions. Meanwhile, Thomson's concern about the uncertain future of palaeontology (and, by extension, biological systematics), and more particularly the infrastructure of collections and taxonomic teaching and research, has increasingly been taken up into serious public debate.

Thomson himself is far from being elderly, as anyone who has met him knows. Yet it is a shock to realize that he crossed the Atlantic not in a Boeing 747 but in the Mauretania (a pre-1914 Cunard steam turbine liner now little more than some wood panelling in a Bristol wine bar). His autobiographical sketch of how a boy became a scientist restates the need for personal inspiration and encouragement from real teachers.

Thomson is so succinct that one is sometimes left wanting more, although this is a useful reminder of the merits of brevity. Whether one prefers his mannered essay-like style, supplemented by Linda Thomson's tenebrous drawings, to Dawkins or Desowitz, Gould or Thomas, is a matter of taste, but it all adds to authorial biodiversity. One quibble: nonscientists will enjoy most of the book, but not quite all - a nonbiologist may be defeated by the unillustrated discussion of the embryonic neural crest, that surprising marker of a true vertebrate.

Meanwhile, Thomson takes time off from the problems of science and the biosphere to take a simple pleasure in diversity. I doubt whether anyone is familiar with every topic here: the lost tree Franklinia, the mysterious fossil Palaeospondylus (fish? amphibian?) found in great abundance in just one Scottish quarry, Gilbert White, Piltdown Man, horse riding and current thinking on tetrapod origins, to name a few. Try these essays for bedtime: you can't go far wrong.

Michael Taylor is in the Department of Geology, National Museums of Scotland, Chambers Street, Edinburgh EH1 UF, UK.

\section{Beastly beliefs}

Mary Midgley

Animal Minds and Human Morals: The Origins of the Western Debate. By Richard Sorabji. Duckworth: 1993. Pp. 267. 135 , \$39.95. Distributed in the United States by Cornell University Press.

READERS of Nature will agree that it is a good thing to discover reasons for our beliefs, even when we are sure about them already. But discovering reasons can sometimes be surprisingly hard and - still more annoyingly - sometimes the reasons already given turn out to be bad ones, so that we must start the job afresh. That was what happened to Richard can string the signs together syntactically. This is a point of the highest scientific interest but of no moral relevance whatever. (Italics added.)

The quest, in fact, turned out not to be just an historical one but a live issue. It is indeed astonishing how, when one looks at these arguments, one finds the same confusions that plagued the Greeks still present, fossilized and essentially unchanged, at the core of much present-day thinking. They still distort our ideas, not just about animals, but human psychology and our relationship with nature.

Centrally, the Greeks' tremendous exaltation of the human intellect inclined them to divorce it altogether from the physical world. This exaltation of thought has of course brought us untold benefits, including the invention of science. But it

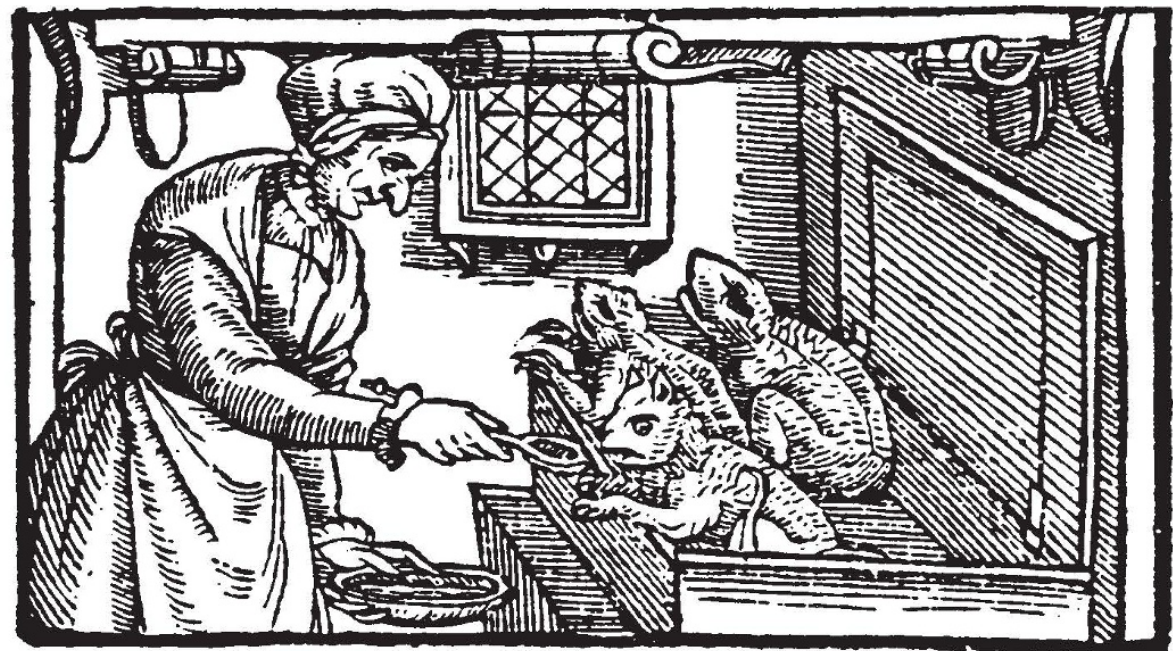

A witch feeding familiars - "A Rehearsall both straung and true, of hainous and horrible actes committed by Elizabeth Stile, Alias Rockingham, Mother Dutten, Mother Devell, Mother Margaret, Fower notorious Witches, apprehended at winsmore in the Countie of Barks, and at Abbington arraigned, condemned, and executed on the 26 daye of Februarie laste Anno. 1579. London". Taken from Animals and Human Society: Changing Perspectives ed. A. Manning and J. Serpell (Routledge, £35).

Sorabji when he started to investigate the reasons that Greek philosophers cited for their belief that humans may do anything they like to animals. As he says:

I began my reading with only a historical interest in the large, and largely uncharted, ancient debate on human and animal psychology. But I was led to appreciate that there was a real, live moral problem by the badness of the arguments for a major difference between animals and man. It sounded grand enough when Aristotle and the Stoics declared that man had reason and animals had not. But, as the debate progressed, it began to appear that animals might lack only certain kinds of reasoning, and a stand was taken on their not having speech. When this defence too began to be questioned, a retreat was made to the position that they lacked syntax. 'They lack syntax, so we can eat them,' was meant to be the conclusion. It was amazing to find that modern discussions had reached exactly the same point as the ancient ones. . . . The debate on the ability of chimpanzees to use sign language has come down to the question whether they distorted the view held of our own species. It moved Homo sapiens away from his shaky, midway status between beasts and gods into a closer and much more ambitious alliance with the latter. Human reason, now hailed as divine, increasingly tried to distance itself from its poor relations both in other human faculties and in the outside world. Any mental likeness between humans and animals, which still formed the irremovable lower pole of the contrast, embarrassed this attempt terribly. Likenesses, therefore, were strenuously minimized.

Sorabji shows how this bias led even Aristotle, who as a biologist stressed the continuity between all lifeforms, to make unreal distinctions between the obviously intelligent behaviour of some animals and very similar behaviour in humans. Using the Greek equivalent of modern shudderquotes, Aristotle kept ruling that such likenesses must somehow be just analogies. Here, already, the concept of reason 
was becoming distorted by idealization, and the abstract, unreal notion of a standard, thought-free 'animal' was supplying a simple contrast to it.

The Stoics, however, carried this process much further, and the Stoic view, which was strongly biased by moral considerations, was the one that St Augustine incorporated into Christian thought. That is why disputants still often rely on it today. (Other Greek thinkers, such as Porphyry, who defended animals, were largely forgotten). For the Stoics, reason played a central part in morals. Reason was the sole basis of duty because it united all rational beings in a supranational community. As far as human life went, this was a noble concept which did much to discredit slavery. But it excluded irrational beings and allowed of nothing intermediate. Stoic theorists therefore argued determinedly that animals could not reason at all. This led them constantly to give strange and distorted definitions both of reason itself and of the various other faculties, such as perception and emotion, that might be brought in to do its work. They thus drove a gratuitous wedge between reason and the rest of the human personality, producing a wide gap that still gives trouble today.

Questions about animals are not, then, just an amusing extra. Their distortion has seriously harmed our thinking. Oversimplification of the moral issue is of course only one aspect of this distortion, but, as Sorabji says, it is one that can scarcely fail to strike us once we notice the confusions that have concealed it. We cannot today treat all our duties, Stoic-fashion, as pure tributes to the rationality of others, still less to their syntactical abilities. The first question we would now naturally ask is, as Jeremy Bentham rightly said, not 'can they speak?' or 'can they reason?' but 'can they suffer?' More widely, the Darwinian continuity that we now recognize between Homo sapiens and other species radically shifts the burden of proof from those who see possible connections to those who deny them a priori.

Sorabji does not offer any simply moral conclusions. He is rightly critical of the rather crude, sweeping 'moral theories' proposed by pro-animal philosophers such as Tom Regan and Peter Singer. But he is sure that the traditional policy of ignoring this issue is not compatible with the kind of moral principles we now live by. We do have to think the matter out afresh. And many scientists, I think, would now agree.

This is an impressive, important and thought-provoking book. It is clearly written and, although much of it deals with the details of Greek thought, the structure is plain and the index is excellent.

Mary Midgley is at $1 A$ Collingwood Terrace, Newcastle-upon-Tyne, NE2 2JP, UK.

\section{On the edge}

\section{Malcolm W. Browne}

A Positron Named Priscilla: Scientific Discovery at the Frontier. By Marcia Bartusiak et al. National Academy Press: 1994. Pp. 348. \$29.95.

ALL too often, omnibus science samplers intended for lay readers consist of breezy, easily digestible chapters on black holes, dinosaur lifestyles, insect navigation, dolphin communication, space travel, ecological issues and the like; they contain precious little to nourish the minds of people interested in the details of physical science, including (perish the thought) a few illustrative equations. A Positron Named Priscilla is a delightful exception, and (for the most part) a pleasure to read.

The whimsical title refers to an experiment conducted in the late 1980 s by Hans Dehmelt at the University of Washington, who succeeded in trapping and immobilizing a single positron using electric and magnetic fields. As he conducted precise measurements of his caged blob of antimatter, Dehmelt named it Priscilla, explaining in his Science paper (as quoted in the book) that "the well-defined identity of this elementary particle is something fundamentally new, which deserves to be recognized by being given a name, just as pets are given names of persons".

Dehmelt's work is described in one of two excellent esssays in this collection by T. A. Heppenheimer - the first on new laboratory implements (such as the scanning tunnelling microscope) that can manipulate single ions, neutral atoms and particles, and the second on the quest by particle physicists for the elusive top quark and the Higgs boson.

Heppenheimer, like the authors of the other eight essays in this collection, starts his discourse with some easily grasped ideas, from which he gently leads the reader into the thickets. The tour takes one through a fascinating labyrinth of interconnected research, historical turning points, personalities and problems, and makes it easier to place new scientific developments into perspective as they come along.

The quality of writing in these sophisticated essays varies; a few of the authors might have remembered that effective prose requires more than merely getting the facts right. A small problem with several chapters is the intrusion of jargon; 'difficult' becomes 'non-trivial' and a number is 'plugged in' rather than 'substituted'. Also, a few writers occasionally try to explain something by merely labelling it. Some of the biochemistry may glaze the eyes of readers confronting a dense alphabet soup of substances known by their three-letter labels - names familiar to specialists but confusing to outsiders.

But most of the book is remarkably lucid. An example of science writing at its best is an essay by Barbara Burke on some of the mathematical tools used to extract signals from mountains of noise. She shows how these tools help to track submarines, catalogue fingerprints, sort out faint radio signals from celestial objects and even reconstruct the primitive and crumbling recording of an original piano performance by Brahms. From such examples she leads the reader into commendably clear explanations of Fourier analysis, and then to a new mathematical entity called the 'wavelet', which, in the hands of an adept, can supposedly "cut the weeds and spare the daisies".

Although many fields of research are ignored, the chosen subjects are compelling because all of them deal with work in progress. Each essay describes conspicuous accomplishments but leaves the disquieting impression that ultimate success is by no means assured.

An essay by Michelle Hoffman about the diabolical tricks devised by the chameleon-like HIV virus to overwhelm a person's immune system, points to some promising potential defences, but also explains why some scientists believe that a cure for AIDS may never be developed.

Indeed, some of the fields may already have hit major obstacles. The demise of the Superconducting Super Collider has dealt a heavy blow to hopes of identifying the Higgs mechanism - a theoretical pillar of the Standard Model and the putative universal giver of mass. And in earthquake forecasting, geologists and seismologists may have to accept that reliable, short-term predictions of earthquakes are intrinsically impossible. It may be that the timing of an earthquake is critically dependent on undetectably small differences in initial conditions that in essence earthquakes are chaotic.

Other fields of research, enriched by new devices, techniques and discoveries, are booming. Marcia Bartusiak offers an exciting glimpse of the astonishing precision of Doppler interferometry in detecting the vibrational modes of the Sun, vibrations that reveal the deep, hidden mechanisms that power stars.

In chemistry, the discovery that carbon atoms can join together as the footballshaped molecules called fullerenes has created a field of investigation as potentially rich as the one that evolved from the discovery of the structure of benzene.

This is a breathtaking overview of some of the most exciting facets of science at the turn of the century, and there's gold to be mined here, whether the reader is a scientific specialist curious about alien fields of research or merely a science buff.

Malcolm W. Browne is a science writer on The New York Times. 